\title{
Progress and Challenges With Warn-On-Forecast
}

\author{
David J. Stensrud ${ }^{1}$, Nusrat Yussouf ${ }^{1,2}$, Dustan Wheatley ${ }^{1,2}$, and Jidong Gao ${ }^{1}$ \\ ${ }^{I}$ NOAA/National Severe Storms Laboratory, Norman, Oklahoma USA \\ ${ }^{2}$ Cooperative Institute for Mesoscale Meteorological Studies, Norman, Oklahoma USA
}

\section{INTRODUCTION*}

Warn-on-Forecast is a ten-year National Oceanic and Atmospheric Administration (NOAA) project to extend severe weather warning lead times by incorporating forecasts from a convection-permitting ensemble modeling system into the warning decision process (Stensrud et al. 2009). Currently, tornado warnings in the United States are issued when a tornado is indicated by radar observations, reported by spotters, or deemed imminent based upon NWS forecaster knowledge of the storm environment, past storm behavior and other environmental clues. This warning paradigm is often called warn on detection and yielded mean tornado warning lead times of 14 minutes during 2010.

One NOAA strategic mission goal is to extend tornado warning lead times to reduce the loss of life, injury and economic costs of high-impact weather events. In order to reach this goal, a new warning paradigm is needed beyond warn on detection. Research results over the past decade suggest that a convective-scale warn-on-forecast paradigm, in which an ensemble of numerical forecasts (initialized using radar observations) provides warning guidance, could be used to meet this NOAA mission goal.

\section{STATUS}

Initial results with convection-permitting ensembles that assimilate radar observations have shown that while reasonable thunderstorm analyses are produced, obtaining accurate very short-range thunderstorm forecasts is more challenging (Snyder and Zhang 2003; Dowell et al. 2004b; Tong and Xue 2005; Yussouf and Stensrud 2010; Aksoy et al. 2010). Model error is often blamed as the dominant source in the loss of forecast skill, especially inaccuracies in the model microphysical parameterizations. Observational studies indicate that the densities and intercept parameters of hydrometeor distributions can vary widely among storms and even within a single storm (Joss and Waldvogel 1969; Pruppacher and Klett 1978; Knight et al. 1982; Ziegler et al. 1983; Cheng et al. 1985; Cifelli et al. 2000). Therefore, assuming a fixed set of microphysical parameters in a convection-permitting numerical model can lead to significant errors in not only the forecasts but also the analyses of severe storm events.

* Corresponding author address: David J. Stensrud, NOAA/NSSL, National Weather Center, 120 David L. Boren Blvd., Norman, OK 73072. Email: David.Stensrud@noaa.gov
To explore the impact of variations in parameters within the same microphysics scheme, several observing system simulation experiments (OSSEs) are conducted using a range of different realizations of the hydrometeor intercept and density parameters. Results highlight the potential for using a variety of realistic microphysical parameters across the ensemble members in improving the analyses and very short-range forecasts of severe weather events (Fig. 1). This is true for both the ensemble mean and when looking at extreme events within the ensembles (Yussouf and Stensrud 2011).
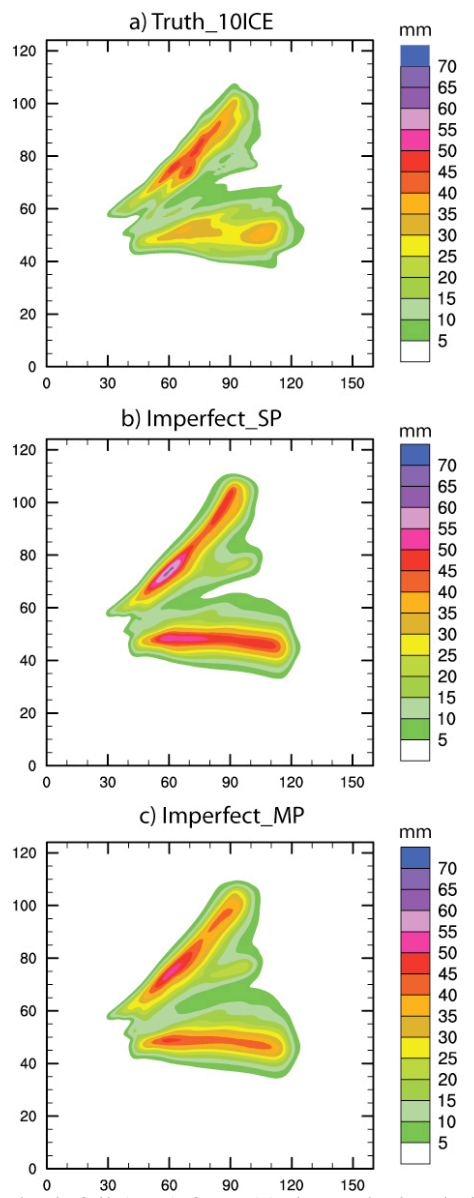

Figure 1. Total rainfall (mm) from (a) the truth simulation, (b) the ensemble mean in which a different microphysical parameterization is used with a fixed single set of parameters, and (c) the ensemble mean in which a different microphysical parameterization is used with the parameters varied. Synthetic radar data from the truth simulation are used to initialize the ensemble simulations (from Yussouf and Stensrud 2011). 


\section{CHALLENGES}

While research into variational and ensemble-based radar data assimilation will continue, there also is a need to demonstrate the potential value of this type of approach in a quasi-operational environment. Storm analyses produced by a three-dimensional variational (3DVAR) assimilation scheme using all available radar observations have been created in real-time and evaluated within the NOAA Hazardous Weather Testbed (Smith et al. 2010; Stensrud et al. 2010). Not only does the 3DVAR produce high-quality analyses, the additional information provided to the forecasters, such as vertical motion fields, have been found to be yield valuable information. Social science research also is needed to determine how best to use ensemblederived probability information in the warning process and its subsequent delivery to the public.

Other challenges for Warn-on-Forecast involve how to design an ensemble for convection-permitting resolutions and needed improvements to model physical process schemes. It is also well known that environmental conditions influence the quality of storm-scale analyses and forecasts (Stensrud and Gao 2010), and so improvements to short-term forecasts of storm environments also are needed.

\section{ACKNOWLEDGMENTS}

The authors thank all the members of the Warn-on-Forecast and Hazardous Weather Testbed teams for their support, contributions and assistance.

\section{REFERENCES}

Aksoy, A., D. Dowell and C. Snyder, 2010: A multi-case comparative assessment of the ensemble Kalman filter for assimilation of radar observations. Part II: Shortrange ensemble forecasts. Mon. Wea. Rev., 137, 12731292.

Cheng, L., M. English, and R. Wong, 1985: Hailstone size distributions and their relationship to storm thermodynamics. J. Climate Appl. Meteor., 24, 1059-1067.

Cifelli, R., C. R. Williams, D. K. Rajopadhyaya, S. K. Avery, K. S. Gage, and P. T. May, 2000: Drop-size distribution characteristics in tropical mesoscale convective systems. J. Appl. Meteor., 39, 760-777.

Dowell, D.C., L. J. Wicker, and D. J. Stensrud, 2004b: High resolution analyses of the 8 May 2003 Oklahoma City storm. Part II: EnKF data assimilation and forecast experiments. Preprints, 22nd Conf. Severe Local Storms, Hyannis, MA, Amer. Meteor. Soc.

Joss, J., and A. Waldvogel, 1969: Raindrop size distribution and sampling size errors. $J$. Atmos. Sci., 26, 566-569.

Knight, C. A., W. A. Cooper, D. W. Breed, I. R. Paluch, P. L. Smith, and G. Vali, 1982: Microphysics. Hailstorms of the Central High Plains, C. Knight and P. Squires, Eds., Vol. 1, Colorado Associated University Press, 151-193.

Pruppacher, H. R., and J. D. Klett, 1978: Microphysics of Clouds and Precipitation. Reidel, $714 \mathrm{pp}$.

Smith, T.M., K. M. Kuhlman, K. L. Ortega, K. L. Manross, D. W. Burgess. J. Gao, and D.J. Stensrud, 2010: A survey of real-time 3DVAR analyses conducted during the 2010 experimental warning program spring experiment. $25^{\text {th }}$ Conf. on Severe Local Storms, Denver, Co, Amer. Meteor. Soc., Paper P5.7.

Snyder, C. and F. Zhang, 2003: Assimilation of simulated Doppler radar observations with an ensemble Kalman filter. Mon. Wea. Rev., 131, 1663-1677.

Stensrud, D. J., and Coauthors, 2009: Convective-scale warn-on-forecast system: A vision for 2020. Bull. Amer. Meteor. Soc., 90, 1487-1499.

Stensrud, D. J., and J. Gao, 2010: Importance of Horizontally Inhomogeneous Environmental Initial Conditions to Ensemble Storm-Scale Radar Data Assimilation and Very Short-Range Forecasts. Mon. Wea. Rev., 138, 1250-1272.

Stensrud, D.J., J. Gao, T.M. Smith, K. Manross, J. Grogden, and V. Lakshmanan, 2010: A realtime weatheradaptive 3DVAR analysis system with automatic storm positioning and on-demand capability. $25^{\text {th }}$ Conf. on Severe Local Storms, Denver, CO, Amer. Meteor. Soc., Paper 8B.1.

Tong, M. and M. Xue, 2005: Ensemble Kalman filter assimilation of Doppler radar data with a compressible nonhydrostatic model: OSS experiments. Mon. Wea. Rev., 133, 1789-1807.

Yussouf, N., and D. J. Stensrud, 2010: Impact of Phased Array Radar Observations over a Short Assimilation Period: Observing System Simulation Experiments Using Ensemble Kalman Filter. Mon. Wea. Rev., 138, 517-538.

Yussouf, N., and D.J. Stensrud, 2011: Comparison of single-parameter and multi-parameter ensembles for assimilation of radar observations using the ensemble Kalman filter. Mon. Wea. Rev., in press.

Ziegler, C. L., P. S. Ray, and N. C. Knight, 1983: Hail growth in an Oklahoma multicell storm. J. Atmos. Sci., 40, 1768-1791. 